\title{
Pseudo-first-order equation
}

Pseudo-first-order equation has been widely used for analyzing the adsorption of an adsorbate from an aqueous solution following Eq (1):

$\log \left(q_{e}-q_{t}\right)=\log q_{e}-\frac{t k_{1}}{2.303}(1)$

Where $q_{e}$ and $q_{t}$ are the amounts of heavy metal ions adsorbed ( $\mathrm{mg} \mathrm{g}^{-1}$ ) at equilibrium and at time $t$ (min), respectively, and $k_{1}\left(\mathrm{~min}^{-1}\right)$ is the rate constant adsorption. Values of $k_{1}$ are calculated from the plots of $\log \left(q_{\mathrm{e}}-q_{\mathrm{t}}\right)$ versus $t$ for the live and dead biosorbents. 